\title{
Feasibility Analysis of the Probabilistic Modelling of LCC Based HVDC Equipment Ageing Using Public Data
}

\author{
Document Version \\ Submitted manuscript
}

Link to publication record in Manchester Research Explorer

\section{Citation for published version (APA):}

Vilchis-Rodriguez, D., Levi, V., Barnes, M., \& Gupta, R. (2020). Feasibility Analysis of the Probabilistic Modelling of LCC Based HVDC Equipment Ageing Using Public Data. In The 10th International Conference on Power

Electronics, Machines and Drives: PEMD 2020 (pp. 1-6). [0220] Institution of Engineering and Technology .

\section{Published in:}

The 10th International Conference on Power Electronics, Machines and Drives

\section{Citing this paper}

Please note that where the full-text provided on Manchester Research Explorer is the Author Accepted Manuscript or Proof version this may differ from the final Published version. If citing, it is advised that you check and use the publisher's definitive version.

\section{General rights}

Copyright and moral rights for the publications made accessible in the Research Explorer are retained by the authors and/or other copyright owners and it is a condition of accessing publications that users recognise and abide by the legal requirements associated with these rights.

\section{Takedown policy}

If you believe that this document breaches copyright please refer to the University of Manchester's Takedown Procedures [http://man.ac.uk/04Y6Bo] or contact uml.scholarlycommunications@manchester.ac.uk providing relevant details, so we can investigate your claim.

\section{OPEN ACCESS}




\title{
FEASIBILITY ANALYSIS OF THE PROBABILISTIC MODELLING OF LCC BASED HVDC EQUIPMENT AGEING USING PUBLIC DATA Damian S. Vilchis-Rodriguez ${ }^{1 *}$, Victor Levi', Robin Gupta ${ }^{2}$, Mike Barnes ${ }^{1}$
}

\author{
${ }^{1}$ Department of Electrical and Electronic Engineering, Power \& Energy Division, The University of \\ Manchester, Sackville Street Building, M13 MPL, Manchester, UK \\ ${ }^{2}$ National Grid, National Grid House, Warwick Technology Park, Gallows Hill, CV34 6DA, Warwick, UK \\ *Damian.Vilchis-Rodriguez@manchester.ac.uk
}

Keywords: HVDC, LCC, reliability analysis, equipment ageing, data collating.

\begin{abstract}
A component's risk of failure increases with age. Therefore for the design of effective, risk based maintenance policies the ageing rate of the system and their constituting components must be considered. However chronologically ordered failure data is seldom publicly available. This paper explores the possibility of using publicly available empirical failure data to construct probabilistic reliability indicators for the main components of line-commutated-converter (LCC) based HVDC systems.
\end{abstract}

\section{Introduction}

During normal operation, systems experience a quasiconstant failure rate (bottom section of the bathtub curve in Fig. 1). During this phase, most of the failures that occur may be considered completely random, thus for maintenance purposes, the frequency of failure may be used as a good indicator to estimate inventory levels required for periodic, corrective maintenance. However, in real-life complex systems, each component is subjected to different types and magnitudes of stresses. Thus, not all the system components or subsystems age at the same rate. Furthermore as a component/system ages, frequency-of-failure tends to monotonically increase, reflecting what is called the wear-out or end of life phase of the component/system (right side in Fig. 1). In that respect, a monotonically increasing failure rate function within the wear-out period is usually considered. Ageing of different system components described by "appropriate" hazard functions needs to be taken into account for the design of effective, risk based maintenance and replacement strategies. Survival analysis can be used in the design of risk based maintenance and replacement strategies [1]. To this end detailed, chronologically ordered failure data is required to construct survival curves and track system reliability evolution. However, access to detailed, chronologically ordered failure data from HVDC systems at component level is very limited. Conversely, HVDC failure data at subsystem level is publicly available in periodic reports produced by CIGRE [2]. These reports were used in this work since they form the most extensive source of failure data for LCC based HVDC systems and their components. The possibility of using the available empirical failure data from CIGRE reports to construct expected failure rates as a function of age (i.e. instantaneous risk) for the main HVDC subsystems and components is explored in this paper. Limitations in the applicability of the available data and the proposed failure rate functions are also presented.

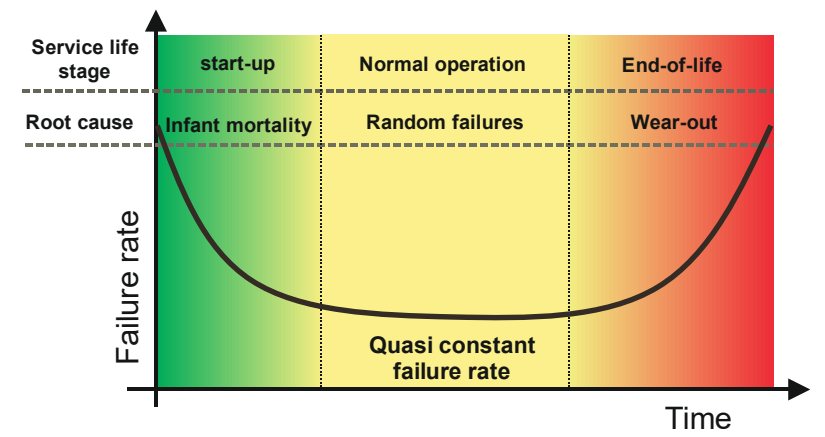

Fig. 1 Bathtub curve

\section{Data collating}

An HVDC link is a complex, repairable system which is in turn comprised by complex, repairable subsystems, where each component within each subsystem ages at a different rate. In general, in the event of a failure, a repairable system can be put back to a working condition after repairs are conducted. However since it is common practice that only failed components are repaired or replaced, it is envisaged that following repairs processes in a repairable system are possible: a) As-bad-as-old (minimal repair); b) Better-thanold (imperfect or better than minimal repair); and c) As-goodas-new (perfect repair, or replacement). Beside the replaced/repaired component or subsystem, all the other system components remain in the same old condition. This continuous repair/renewal process of the system components has the potential to alter the system failure rate; therefore in a repairable system, failure rate tends to vary with time [3]. A system where the failure rate is time dependant can be considered a non-homogenous Poisson process (NHPP) [3]. In this report the HVDC link and its constitutive subsystems will be considered as NHPPs.

The CIGRE reports depend entirely on the voluntary response from utilities and operators, therefore HVDC 
systems are being added and removed constantly. Hence the number of, and sub-types of systems, included in each report vary considerably, giving incomplete, left-, right- and interval-censored failure data. In survival analysis it is defined that the data is left-censored when the event of interest already occurred, right-censored if the event of interest did not occur during the observation period, and interval-censored if the event (failure) occurred within some given time window during the observation period, however the exact time is unknown [4]. Given the multi-censored nature of the employed failure data, a weighted reliability indicator, fault intensity, is used in this analysis. In the reliability analysis of repairable systems the rate of occurrence of failure (ROCOF) vs system age is known as the "intensity function" (or "hazard function") and is commonly used as an indicator of the system reliability. In succinct terms, failure intensity is the expected number of occurrences a system will fail in a specified time period.

In order to facilitate the analysis, the system age at each reported year is calculated, and the annual failure rate against system age is obtained. The system age is defined here as the difference between the reported year and the HVDC system commissioning year, for each CIGRE report. Thus a single system will be accounted for in as many age groups as its annual failure data for different years have been reported. Systems in the $300-500 \mathrm{kV}$ ac/dc category are considered in the analysis.

\section{Ageing effects}

Fig. 2 shows the ROCOF for all the HVDC systems included in the CIGRE reports for the period 2001-2016 for the category under analysis. As can be seen in the figure, a decrease in the number of failures seems to occur as the system ages, which contradicts the notion of ageing. This result implies that the ageing information contained in the failure data under analysis is not significant, or is otherwise masked by dominant random failures or by current maintenance practices. Given the limitations exhibited in the analysed data, attempts were made to utilize the very limited information at component level provided in the various CIGRE reports. The effort was particularly focussed on the HVDC converter, given that more detailed performance information for this subsystem is included in such reports.

\subsection{Converter valves}

The converter is the heart of the HVDC system. Unsurprisingly, several of the statistics included on the CIGRE HVDC survey reports are related to converter performance. In this section, the statistics available in the HVDC CIGRE survey reports, related to converter reliability performance, are analysed with the aim of constructing a picture of the converter components' reliability as functions of the system age. Fig. 3 shows the failure intensity calculated using the CIGRE failure data from 2001-2016 for the converter valve subsystem (V) for systems grouped in the $300-500 \mathrm{kV}$ category. The $\mathrm{V}$ system failures reported by the CIGRE include combined failures for the converter electrical and cooling system.

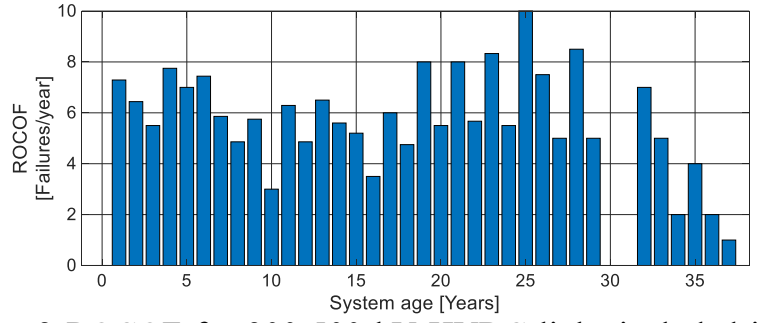

Fig. 2 ROCOF for $300-500 \mathrm{kV}$ HVDC links included in the CIGRE reports from 2001-2016

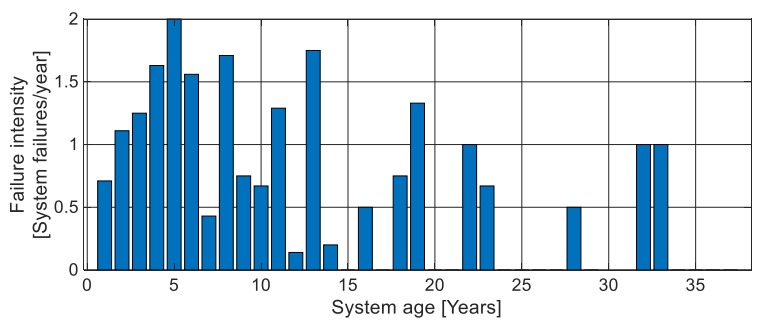

Fig. 3 Converter valve (V) subsystem failure intensity by age group for LCC systems in the $300-500 \mathrm{kV} \mathrm{AC/DC}$ range

As can be seen in Fig. 3, the failure intensity of the $\mathrm{V}$ subsystem does not show signs of increasing failure rate with age (which would be indicative of a system reaching the wear-out phase). On the contrary, the failure intensity appears to decrease as system age increases. It may be argued that the multi-censored and aggregated nature of the failure data used in the analysis turns difficult the identification of ageing effects. For instance, the number of systems vary greatly between reports and, as mentioned before, the employed failure data aggregates cooling and electrical failures. In fact, the cooling and electrical sub-systems have quite different lifetime expectancies, 15 and 30 years respectively [5]; failure and ageing rates for these subsystems should also be different. Such dissimilarities imply that refurbishment of these subsystems should occur at different stages on the lifetime of an HVDC system. Consequently, the possibility exist for a subsystems to be relatively "new" even at an advanced stage on the HVDC link lifetime. Hence, maintenance and replacement policies have the potential to mask ageing effects on the system's failure data. Another plausible explanation for the observed behaviour in the failure data is that given the relatively young age of the majority of the HVDC systems considered, random failures are still predominant. In any case, failure effects related to the ageing of the $\mathrm{V}$ sub-system are not identifiable in the analysed data set. This is the reason why a different set of failure data related to converter reliability performance is analysed below.

Another indicator related to the HVDC converter reliability performance provided in the CIGRE reports is the number of failed converter cells. In a converter, each valve is comprised of a number of series connected thyristor levels, which in turn consist of a series of thyristor cells. A thyristor cell is an individual thyristor and associated auxiliary circuits, whereas a thyristor level is the assembly of one or more thyristor cells connected in parallel (if needed), including associated circuits. Additionally, each thyristor level includes a gate 
electronics unit and associated damping and DC grading circuits. The number of series connected thyristor levels in a valve depends largely on the system voltage. The converter cell can be considered the essential building block of the converter valve. Recognizing that the cell voltage is independent of the DC link voltage, the analysed data considers all the LCC systems included in the HVDC reliability CIGRE survey reports [2] between the years 19862016. This large dataset is expected to highlight any identifiable trend, showing any reliability tendency. The percentage of failed cells by age group for all the systems included in the CIGRE reports from 1986-2016 is shown in Fig. 4. As can be seen in Fig. 4, a surprisingly regular pattern emerged by using this large dataset. In the figure local maxima can be identified at years 3,15 and 27 with a 12 year period between them. This periodic behaviour is typical of repairable systems, where after maintenance a temporary decrease of the failure rate usually occurs. However, a thyristor cell on its own cannot be considered a repairable system: a failed thyristor cell or group should be expected to be replaced with a new unit during the next planned maintenance period. Thus the cyclic behaviour suggests the influence of an auxiliary, repairable subsystem on the thyristor cell reliability. Interestingly, cooling systems have an expected lifetime in the range of 15 years [5], and therefore their overhaul is expected to occur near their endof-life. Thus the incidence of the health of the converter cells from a slowly degrading cooling system may explain this periodic behaviour. It is also clear in the figure that after 26 years, the thyristor cell failure rate increases considerably: the local maximum at year 27 is twice the value of the local maxima between 0 and 26 years of age. Thus, although the percentage of failed cells remains relatively low (less than $0.5 \%$ ), this relatively steep increase in failures may indicate the start of a more pronounced deterioration phase, which incidentally coincides with the expected 30-40 years of converter design lifetime.

It should be noted that the global maximum observed in Fig. 4 was consequence of a single severe event that resulted in the damage of many cells in a single installation, and it is not necessarily a reflection of system ageing. Nevertheless, if the global maximum at year 32 is ignored, it is also clear that after year 27 a decrease of the percentage of failed cells is again observed. However, random variations in the percentage of failed cells seem to occur after such age. In this way the very ordered pattern preserved until such point is somewhat lost. It ought to be mentioned that the number of cells and systems in the sample data older than 34 years is relatively small (Fig. 5). Given the relatively small data set for this cell age group excessive sensitivity to mild, local events is expected. However this extra sensitivity does not completely explain the irregular pattern observed for cells that are between 27 and 34 years old. It may be argued that this disordered pattern signals the simultaneous entry of several components of the thyristor cell, or any other of the converter auxiliary subsystems, into the wear-out phase. However this hypothesis requires more detailed data to be verified.

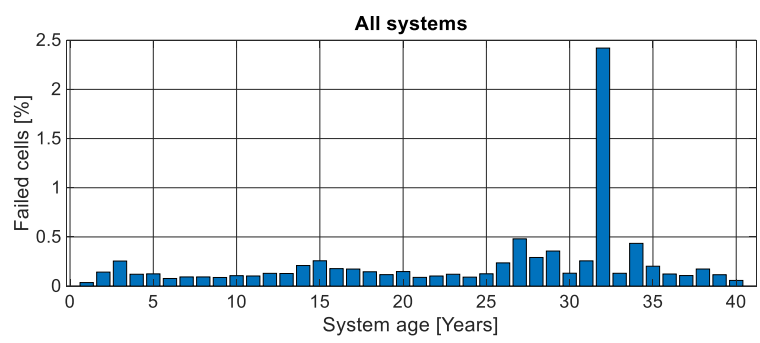

Fig. 4 Percentage of failed thyristor cells by age group for all LCC systems included in the CIGRE reports from 1986 to 2016
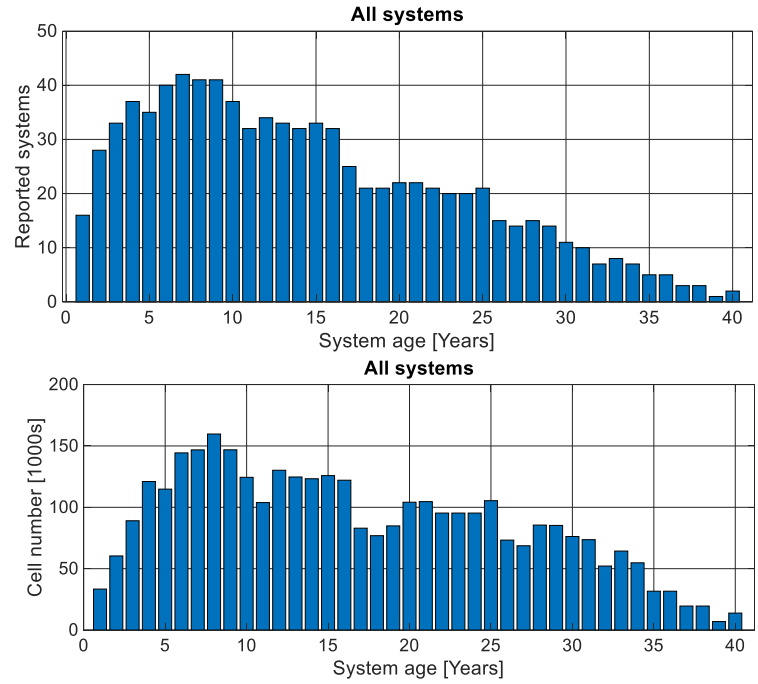

Fig. 5 Number of LCC based HVDC systems (top) and number of thyristor cells by age group (bottom) included in the CIGRE reports from 1986 to 2016

Normally, an LCC based HVDC converter possesses a number of redundant thyristor cells, to ensure its correct and uninterrupted operation in the eventuality of a cell failure. However once the number of failed cells exceeds the redundant cell number, the converter needs to be taken out of service to replace the failed cells. To avoid this unplanned outage, it is common practice to replace failed cells during the scheduled periodic maintenance, e.g. once a year. It may be therefore assumed that after maintenance is completed, $100 \%$ of the thyristor cells in the systems are operational again. Thus some brand new, or as-good-as-new thyristor cells can be potentially added after each year of operation. This constant renewal process implies that even after the designed lifetime of the HVDC system has elapsed, many of the thyristor cells could be relatively new, and remain in excellent condition. Furthermore, potentially, cells of all age groups can coexist in a single converter at the end of the HVDC link expected lifetime. This continuous renewal process, combined with a lack of information regarding the actual age of the failed cell, makes it difficult to construct an accurate thyristor cell survival model. However, certain assumptions can be made to allow such a type of analysis. The following assumptions are used in this report to facilitate thyristor cell survival analysis:

1. In an HVDC system, the sum of failed and operating cells remains constant during any operating year. 
2. Failed thyristor cells are replaced annually; this means that $100 \%$ of the thyristor cells are functional at the start of each year.

3. The annual percentage of failed cells (i.e. hazard rate) is given by Fig. 4 .

4. The percentage of failed cells is evenly distributed between all cell age groups present in the system in each operating year.

An important consequence of the above assumptions is that the percentage of surviving cells can be calculated knowing the percentage of healthy cells at the start of the previous year. Thus an empirical survival curve of the converter cell, based on the Kaplan-Meier method [6] for instance, can be constructed. For example, at the start of year 1 (age 0) $100 \%$ of the original converter cells are in operation. At the start of the second year the percentage of original surviving cells is the percentage of surviving cells at the start of the previous year minus the percentage of failed cells reported during the previous operational year, etc. Similar logic can be recursively applied in subsequent years. The resulting survival curve is shown in Fig. 6. As can be seen in Fig. 6, if the severe fault occurring within the 32 year old systems group is ignored (Fig. 4), the survival curve is quasi linear for the entire period under analysis; this shows a very high cell survival probability even for cells 40 years old. The high survival probability shown in Fig. 6 matches anecdotal evidence and accelerated tests, where even after 40 years of operation, signs of ageing on the thyristor valves have been reported to be minimal $[7,8]$. It can also be seen in Fig. 6 that a slightly more pronounced decline occurs after 26 years of age. Thus although incipient signs of ageing are apparent in the figure, the ageing rate is very slow, particularly when compared with the HVDC link expected lifetime. This low ageing rate may be attributed, for instance, to the fact that the thyristors in a converter cell operate at temperatures well below the levels where a serious decrease in lifetime expectancy could be expected [9]. Thus current maintenance practices can in general be considered to be good enough to guarantee a high availability of converter valves. However with the evidence at hand, it may be convenient to keep a closer eye on the operating condition of the cooling system, since it seems that its degradation may have a measurable influence on the thyristor cell failure rate.

\subsection{Converter transformer}

Owing to the profound impact that the converter transformer (CT) reliability has historically had on LCC HVDC system availability, CT performance has been a constant source of concern for utilities and operators. Moreover, the results available in the CIGRE HVDC performance survey reports show that $\mathrm{CT}$ failures are the largest contributor to the forced energy unavailability (FEU) on LCC HVDC systems. Given its relevance, the CIGRE has conducted a series of surveys specifically focusing on CT performance [10, 11, 12] covering the period 1972-2012. In spite of the 40 years of historic failure data contained in these survey reports, the amount of quality failure data included is very limited. For instance, reports $[11,12]$ mostly provide summarised failure data for the entire periods considered, 1972-1990 and 19912002, respectively. Owing to the lack of granularity and the length of the periods considered, the number of transformers and failure rate by age group cannot be established using the data contained in these reports. In contrast, report [10] provides biannual summaries, covering CT failures reported in the period 2003-2012. Although not ideal, the superior granularity of the failure data contained in [10], compared with that of $[11,12]$, allowed the estimation of CT failure rate by age group. Therefore the analysis presented in this paper is solely based in the CT failure information contained in [10].

As suggested above, additional assumptions still had to be made to enable the grouping of CT failures by age:

1. Given that the age of failed transformers is usually not included in the report, the system age, as defined in section 2 , is used for grouping purposes.

2. Since the failure data is provided on a biannual basis, the age of the system for the reported period can take any of the two values. For grouping purposes, the highest age value assignable to each system is assumed as the system age at the time of the failure.

Based in the above assumptions, the failure data was categorized and processed. Fig. 7 shows the CT-Years by age group for all the systems included in report [10], while Fig. 8 shows the corresponding number of failures. In Fig 8, a failure is considered as 'actual' if removal of the unit from service was required due to the damage, while a 'prevent' failure is the one where the unit did not actually "go dead", but it had to be taken out of service to repair active parts. It should be noted that both, prevented and actual failures can lead to CT replacement, thus the severity of the failure is not necessarily related to its classification. Fig. 9 shows the failure rate by age group for the same dataset used in Fig. 8 .

As can be seen in Fig. 8, most of the CT failures occurred on systems less than ten years old, with a somewhat sustained number of failures occurring in systems that are 10 to 30 years old. However, as illustrated by Fig. 7, this behaviour can be explained by the population age density distribution, because a high number of systems and CTs are younger than 10 years. In contrast, Fig. 9 reveals a sudden increase in failure rate (which is a weighted index) for systems that are 32 and 34 year old. Such behaviour could be interpreted as a sign of ageing. However for such age groups the CT population is rather small and the age groups comprise transformers from a single system (Nelson River BP2 [10]). In addition, the CT years considered for the calculation of the failure rate for such age groups (16 CT-Years) are the lowest of all the age groups considered in this analysis (see Fig. 7). Thus, excessive sensitivity cannot be ruled out as the cause of the sudden spike observed in failure rate (Fig. 9). Therefore, the significance of these spikes in failure rates is debatable. Nevertheless, the failure description included in [10] reveal that several CTs that failed after more than 30 years of operation were retired, mostly for economic reasons rather 
for the actual failure severity: repair was no longer a cost effective solution. This indicates that the economic life of the CTs has been exceeded.

If similar assumptions as those made for the case of the thyristor cells in section 3.1 are considered for the CTs, Kaplan-Meier curves for the transformer population can be constructed using the failure rates shown in Fig. 9. For instance, Fig. 10 shows the probability of having experienced some type of failure by a given age for the CT population under analysis. Fig. 10 shows that by year fifteen it is expected that half of the CT population had experienced some kind of failure (actual or prevented). It is interesting to notice that after year eight the change of the failure probability with age slows considerably, compared to the CT early years. This trend seems to suggest that although LCC technology has been around for more than 40 years, CT infant mortality is still a concern. It should be noted that these curves are not actual "survival" curves, since minor and nonend-of-life failures are also considered in the analysis. For a proper survival analysis, end-of-life CT failures should be considered only. This is the reason why the survival probability of the CTs to major, end-of-life winding failures is separately assessed below.

\subsubsection{Transformer winding failures}

A winding failure can be considered as a major CT failure, since replacement of the failed winding, or even rebuild of the transformer, is usually required after such event. Replacement of the failed winding can increase considerably the CT useful life, and therefore the transformer can be considered as "new equipment" afterwards. Thus for practical purposes, a winding failure may be considered as an end-oflife event. Moreover, electrical insulation is known to degrade with time. Therefore an increase in the number of CT winding failures should be expected to occur as the CT ages. In the same way, $\mathrm{CT}$ failure rates due to winding failures are expected to increase with transformer age, and its end-of-life effect should allow the construction of CT survival curves. Fig. 11 shows the CT failure rates by age groups resulting from $\mathrm{AC}$ and valve side winding failures. The failure rates were calculated using the failure data reported in [10] and neglecting other CT failure types.

Although a tenuous, increasing trend in failure rate with age seems to be depicted in Fig. 11, excessive sensitivity due to the very small number of old transformers included in the sample data cannot be discarded as the cause of the sudden increase in failure rate at year 33. Furthermore, the detailed report in [10] states that for such case six transformer windings, all in the Itaipu system, were fitted with new AC and DC windings as a preventive measure. Thus no actual failure occurred, and therefore the CTs' remaining useful life cannot be unambiguously established. Furthermore, the corresponding Kaplan-Meir curve, shown in Fig. 12, displays an almost linear relationship between the CT survival probability and age. This means that no increase in CT mortality rate with age is noticed in the analysed sample data. Moreover, the median falls beyond the plotted limits, thus acceptable risk limits cannot be established. It can be concluded from these results that not sufficient data is available to produce representative CT survival curves.

Based on the limited data at hand, the survival curve in Fig. 12 suggests that the expected CT lifetime of 45 years stated in [5] is not an unrealistic assumption in practice. However, as happens with other electrical equipment, the CT insulation lifetime will depend on operating conditions and surrounding environment. Therefore the useful life of a CT may vary significantly from installation to installation. For instance, in most of the cases listed in [10], where it was decided not to repair a CT after a failure, the failed CT was 30 years of age or more. On the other hand, very often even older transformers remain in operation, which indicates that not only CT age, but other technical and economic reasons play a key role in adopting such decisions.

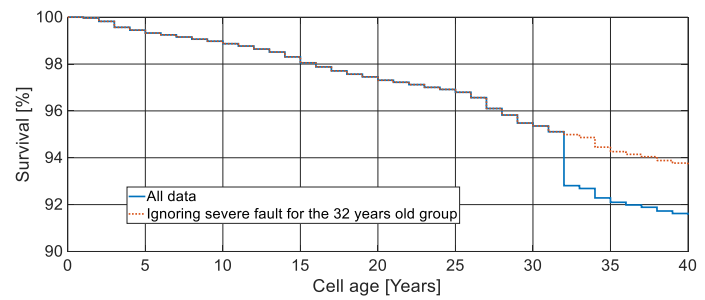

Fig. 6 Thyristor cell survival curve

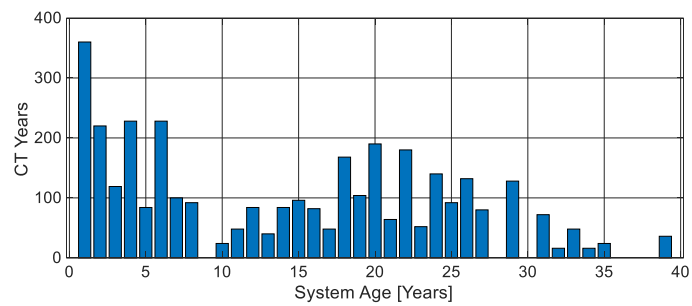

Fig. 7 CT years by system age group

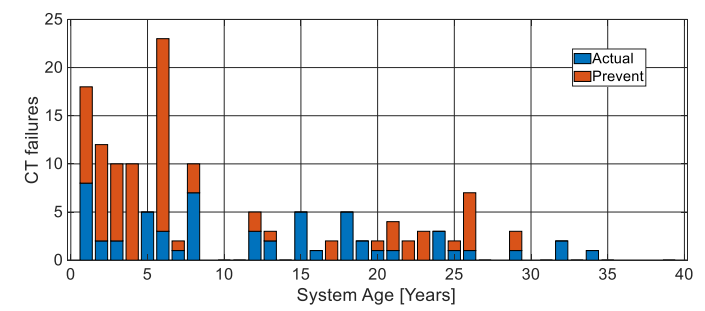

Fig. 8 Number of CT failures by system age group

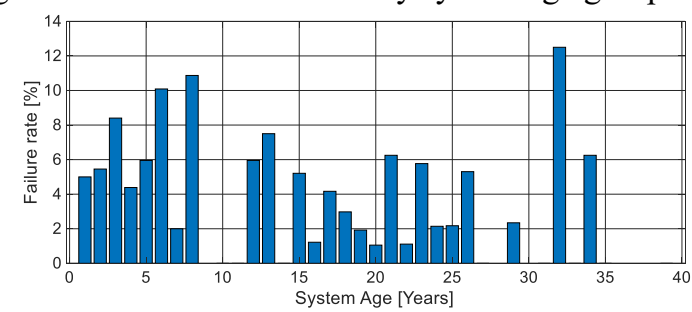

Fig. 9 CT Failure rate by system age group

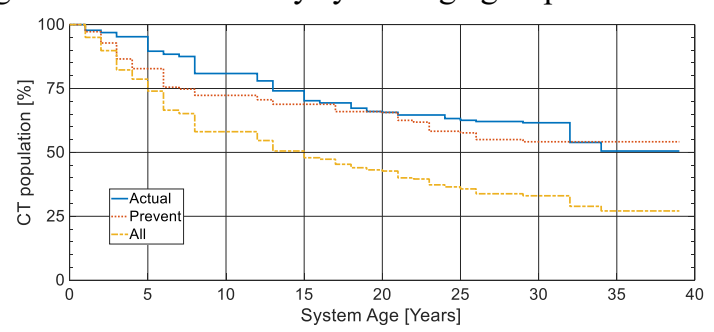

Fig. 10 CT population failures by age 


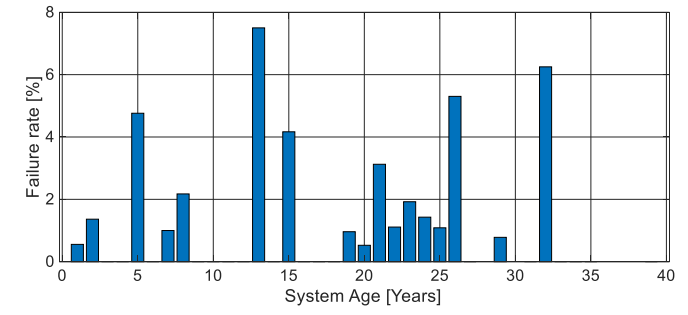

Fig. $11 \mathrm{CT}$ AC/Valve side winding failure rate by age

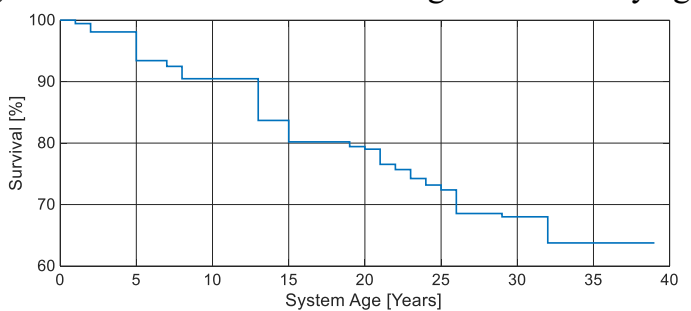

Fig. 12 CT survival probability to winding failure

\section{Conclusion}

The analysis of the historic series of the failure intensity for HVDC systems operating with AC/DC voltages in the 300 $500 \mathrm{kV}$ range revealed no evident sign of ageing. The lack of ageing information in the failure data can be explained in several ways:

1. The aggregate nature of the failure data conceals the ageing information from the system components.

2. The system behaviour is dominated by random failures due to the relatively young age of the most of the HVDC installations, so that ageing effects are not detectable.

3. Current maintenance practices may be masking incipient ageing effects. It may even be that, excessive maintenance and/or premature equipment retirement may be occurring in practice.

The analysis of the thyristor cell failure data revealed the existence of a cyclic pattern in its failure rate related to the system age, exhibiting local unreliability peaks every 12 years. It is argued that this cyclic pattern may be a reflection of slowly degrading auxiliary systems. Interestingly, the 12 year period of the observed reliability cycle is consistent with the expected lifetime of the valve cooling system. This suggests that the slow deterioration of the cooling system could be affecting the converter cell reliability. However, further research is required to confirm this hypothesis. Continuous monitoring of the cooling system performance is therefore recommended.

Survival analysis of the thyristor cells comprising the converter valves revealed an excellent survival probability of more than $90 \%$ after 40 years of operation. This result matches anecdotal evidence where very little signs of ageing have been reported in converter valves with 40 years of operation. Thyristor valves are a mature technology that can survive well beyond the HVDC link expected lifetime when adequately serviced. The survival analysis of any other major
HVDC component was severely impaired by the lack of quality failure data.

\section{Acknowledgements}

This work was funded as part of the National Grid/NIA project "The FMEA Studies and Risk-based Maintenance for Emerging Power Electronics Assets within GB Power Networks".

\section{References}

[1] Winkler, A.: 'A Common Framework for Analysing and Modelling Failure Events', available online, https://www.sveurope.com/wp-content/uploads/2011/07/A-Common-

Framework-for-Analysing-and-Modelling-Failure-Events-2502-2013.pdf, last accessed 13-09-2019.

[2] CIGRE WG B4.04: 'Protocol for Reporting the Operational Performance of HVDC Transmission System', CIGRE TB-590, July 2014.

[3] Doyen, L., Gaudoin, O.: 'Classes of imperfect repair models based on reduction of failure intensity or virtual age', Reliability Engineering and System Safety, vol. 84, no. 1, pp. 45-56, 2004.

[4] Rodrigues, A., Calsavara, V., Silva, F. et al.: 'Use of interval-censored survival data as an alternative to KaplanMeier survival curves: studies of oral lesion occurrence in liver transplants and cancer recurrence', Appl. Cancer Res. vol. 38, no. 16, 2018.

[5] Joseph, T., Ugalde-Loo, C.F., Liang, J., et al.: 'Asset Management Strategies for Power Electronic Converters in Transmission Networks: Application to Hvdc and FACTS Devices', in IEEE Access, vol. 6, pp. 21084-21102, 2018.

[6] Dodson, B., Nolan, D.: 'Reliability Engineering Handbook', New York: Marcel Dekker, Inc, 1999.

[7] 'Thyristors - The heart of HVDC', available online at https://www.abb-conversations.com/2015/11/thyristors-theheart-of-hvdc/. Last accessed 2nd of August 2019.

[8] Sampei, M., Yamada, T., Tanabe, S., et al.: 'Secular change in characteristics of thyristors used in HVDC valve', in IEEE Transactions on Power Delivery, vol. 12, no. 3, pp. 1159-1167, July 1997.

[9] Cepek, M., Krishnayya, C.P.: 'Thyristor aging', POWERCON '98. 1998 Int. Conf. on Power System Technology Proceedings, Beijing, China, 1998, vol. 1, pp. 649-653.

[10] CIGRE Advisory Group B4.04: 'HVDC LCC Converter Transformers, Converter Transformer Failure Survey Results From 2003 To 2012', CIGRE TB-617, April 2015.

[11] CIGRE JTF 12/14.10-01: 'In-Service Performance Of HVDC Converter Transformers And Oil-Cooled Smoothing Reactors', ELECTRA, No. 155, August 1994.

[12] CIGRE JTF B4.04 /A2-1: 'Analysis of HVDC Thyristor Converter Transformer Performance’, CIGRE TB-240, 2004. 